\title{
Highly efficient latent fingerprint detection by eight-dansyl-functionalized octasilsesquioxane nanohybrids
}

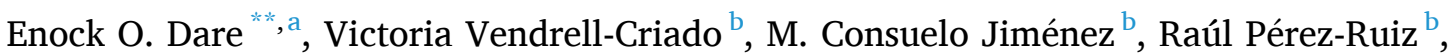 \\ David Díaz Díaz ${ }^{\text {a,c, d,* }}$ \\ a Institute of Organic Chemistry, University of Regensburg Universitätsstr. 31, 93040, Regensburg, Germany \\ ${ }^{\mathrm{b}}$ Departamento de Química, Universitat Politècnica de València, Camino de Vera S/n, 46022, Valencia, Spain \\ ${ }^{\mathrm{c}}$ Departamento de Química Orgánica, Universidad de La Laguna Avda. Astrofísico Francisco Sánchez, 38206, La Laguna, Tenerife, Spain \\ d Instituto Universitario de Bio-Orgánica Antonio González, Universidad de La Laguna, Avda. Astrofísico Francisco Sánchez 2, 38206, La Laguna, Tenerife, Spain
}

\section{A R T I C L E I N F O}

\section{Keywords:}

Fingerprint detection

Silsesquioxanes

Dansyl

Click chemistry

Photostability

\begin{abstract}
A B S T R A C T
The largely demand in continued security issues makes necessary the development of novel materials with outstanding properties to improve the current detection techniques. In this context, latent fingerprint (LF) by fluorescent labeled materials (FLM) is one of the most attractive personnel identification methodologies. Here, two FLM based on polyhedral oligomeric silsesquioxane (POSS) nanohybrids labeled with dansyl chromophores have been synthesized and fully characterized. Their photophysical properties have confirmed that these materials clearly possess the prime qualifications as suitable LF sensing platforms. In fact, they adequately detect LFs on glassy surface with excellence legibility.
\end{abstract}

\section{Introduction}

Fluorescent labeled materials (FLMs) are already being applied in forensic science such as encoding information for anti-counterfeiting, [1] encryption of confidential data [2] or latent fingerprint (LF). [3] The latter appears to be the best option for personal identification due to their uniqueness and complexity of ridge patterns. [4] Despite the fact that nanoparticles are found to be a potential tool for LF detection, [5] development of novel systems is still required in order to finally take them into routine use. Thus, validation of nanoparticles should fulfill three desirable properties at the same time: i) particles with nanometric range (up to $100 \mathrm{~nm}$ ), ii) to be facilely functionalized onto the surface (to permit the selective targeting of fingermark components) and, iii) to have optical properties that facilitate fingermark visualization post development. In this context, some nanohybrids have appeared to suit these characteristics and can be found in the literature. [6,7] For instance, Chen and co-workers [6] developed a nanohybrid which exhibited traffic light-type fluorescence color change when exposed to TNT. Thus, red-emitting Cu-doped $\mathrm{ZnCdS} \mathrm{(Cu-ZnCdS)} \mathrm{quantum} \mathrm{dots}$ were embedded into silica nanoparticles and the green-emitting ZnCdS quantum dots were anchored onto the surface of the silica nanoparticles and further functionalized with poly (allylamine) (PAA). Due to this appropriate structural design, the nanohybrid was capable of both fingerprint staining and drug/explosive visualization. Cui and coworkers [7] synthesized fluorescent carbon and silica nanohybrids in one simple step which resulted in effective FLMs for the image of LFs on a variety of surfaces including e.g. single background color materials (marbles, transparent tape, white ceramic tiles, black plastic pages, stainless steel sheets, and painted wood) and multicolored surfaces (drink bottle foils and fresh fruits); in this particular case a comparative study with benchmark techniques was however missed. Very recently, we have explored the feasibility of a rigid 3D hetero-structural material based on polyhedral oligomeric silsesquioxane (POSS) mono-doped with different chromophores for LF detection (Fig. 1A). [8] We demonstrated that these cubic octameric frameworks (T8) with an adequate cage size $(0.5-0.7 \mathrm{~nm})$, exhibited high stability, excellent biocompatibility in the biological environment $[9,10]$ and effectiveness for LF detection. Fingermark ridges and the interstitial space between them are narrow (ca. $435.5 \pm 57.4 \mu \mathrm{m}$ in width). [11] In theory, the use of nanoparticles could result in greater ridge pattern clarity than using the micron-sized particles in traditional powders that normally contain particles in the submicron to micrometer range. [12] The ability to

\footnotetext{
* Corresponding author. Institute of Organic Chemistry, University of Regensburg Universitätsstr. 31, 93040, Regensburg, Germany.;

$* *$ Corresponding author.

E-mail address: ddiazdiaz@ull.edu.es (D. Díaz Díaz).
} 
deposit a greater number of luminescent nanoparticles along a ridge may also provide enhanced contrast between the ridge and substrate [5]. From a mechanistic point of view, recent studies have shown that hydrophobicity is a major yardstick to fingerprinting development mechanism. $[13,14]$ In this line, the Si-O-Si skeleton clearly provided hydrophobic properties. In addition, labelling with a dansyl fluorophore was carefully chosen considering not only its photophysical properties (very large Stoke's shift and environment sensitivity) but also hydrophobicity of the 3D nanohybrid remained unaltered. The mechanism of detection implied hydrogen-bonding with the residual amino acids in the fingerprints. In view of the necessity of progressing in the forensic science area and the non-stop evolution on constructing new materials for LF application, we have made a step forward into these promising 3D materials which are barely known. The strategy is now based on anchoring to the $\mathrm{Si}-\mathrm{O}-\mathrm{Si}$ skeleton with eight fluorescent chromophores in order to provide it with unprecedent characteristics in terms of photophysical properties, photostability and great effectiveness on LF detection, pointing to favor hydrogen-bonding interactions (Fig. 1A).

In this study, two novel eight-dansyl-functionalized POSS nanohybrids have been successfully synthesized (POSS-D8 and POSS-S-D following a three-step procedure (Fig. 1B). Both nanohybrids fulfil the three prime requisites: i) they are smaller than $100 \mathrm{~nm}$, ii) they can be easily functionalized by simple synthetic routes and, iii) they present excellent optical properties for a successful real LF detection.

\section{Experimental section}

\subsection{Materials}

${ }^{1} \mathrm{H}$ NMR spectra were recorded on a Bruker Avance 300 or $400 \mathrm{MHz}$ spectrometer in $\mathrm{CDCl}_{3}$ or DMSO- $d_{6}$. The residual undeuterated solvent signal was used as reference, relative to the tetramethylsilane signal. ${ }^{13} \mathrm{C}$ NMR were recorded on a Bruker Avance 300 or $400 \mathrm{MHz}$ (respective resonance frequency: 75 and $101 \mathrm{MHz}$ ) under broadband ${ }^{1} \mathrm{H}$ decoupling in $\mathrm{CDCl}_{3}$ or DMSO- $d_{6} .{ }^{29} \mathrm{Si}$ NMR were recorded in the same vein. The residual undeuterated solvent signal was used as reference, relative to the tetramethylsilane signal. ${ }^{1} \mathrm{H}$ NMR and ${ }^{13} \mathrm{C}$ NMR data were reported as follows: Chemical shifts were reported in the $\delta$ scale relative to residual $\mathrm{CDCl}_{3}(7.26 \mathrm{ppm})$ for ${ }^{1} \mathrm{H}$ NMR and to the central line of $\mathrm{CDCl}_{3}$ (77.16 ppm) for ${ }^{13} \mathrm{C}$ NMR. FT-IR spectra were obtained with an Agilent Technologies Cary 630 FT-IR spectrometer equipped with Golden Gate Diamond ATR (attenuated total reflection. All reactions were monitored by thin-layer chromatography using Merck silica gel plates 60 F254; visualization was accomplished with short-wavelength UV light (254 $\mathrm{nm}$ ) and/or staining with appropriate stains (anisaldehyde, orthophosphomolybdic acid). Standard flash chromatography was performed using Macherey-Nagel silica gel of a particle size 40-63 $\mu \mathrm{m}$. 3-Chloropropyltrimethoxylsilane, trichlorovinylsilane, amberlite-R120, 3chloro-1-propanethiol and $N, N, N^{\prime}, N^{\prime \prime}, N^{\prime \prime}$-pentamethyldiethylenetriamine (PMDETA) were purchased from Sigma-Aldrich. All other

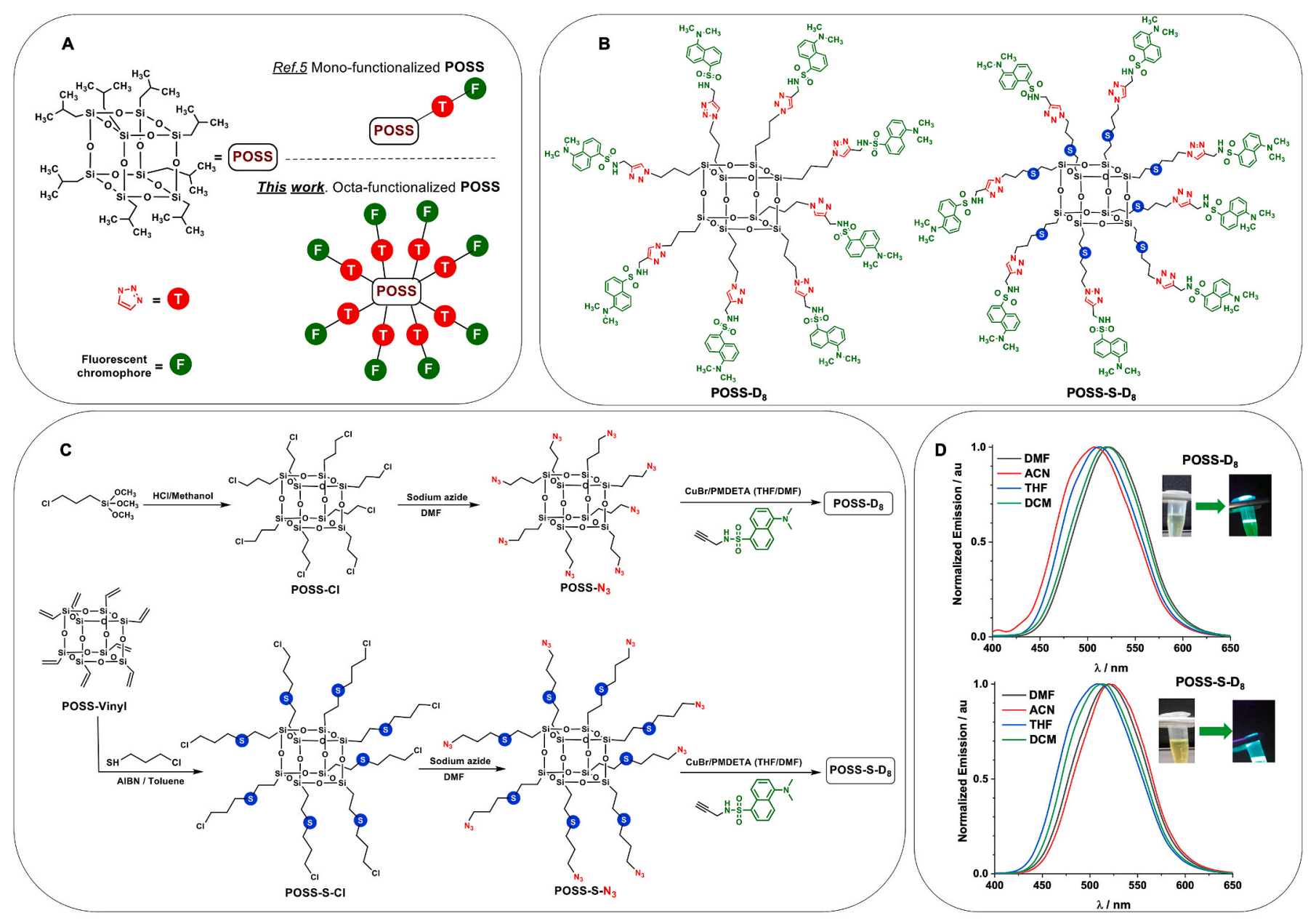

Fig. 1. A) Schematic illustration of the mono- (see ref. 8) and octa-functionalization (this work) of 3D POSS. B) Chemical structures of octakis ( $N$-dansyl-((1-propyl-

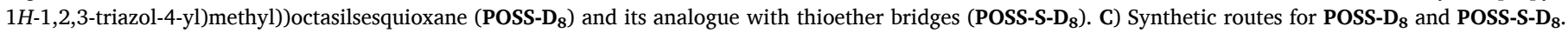

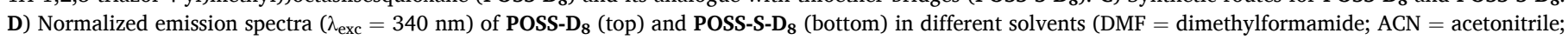

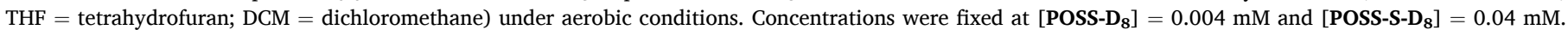
Insets: Photographs of both nanohybrids in solution before and after light exposure. 
commercially available reagents and solvents were used without further purification.

\subsection{Synthesis and characterization of compounds}

Synthesis of alkynyl dansyl derivative: 5-(dimethylamino)- $\mathrm{N}$-(2propynyl)-1-naphthalenesulfonamide ( $N$-dansyl propynyl, D) was prepared according to previous procedure. [15] ${ }^{1} \mathrm{H}$ and ${ }^{13} \mathrm{C}$ NMR spectral data for $\mathbf{D}$ were found to be similar to those found in literature.

Synthesis of octakis (3-chloropropyl)octasilsesquioxane (POSS-Cl): [16] A solution of dry methanol $(150 \mathrm{~mL})$ and concentrated hydrochloric acid $(5 \mathrm{~mL})$ was placed in a two-necked, round-bottomed flask equipped with a condenser, an addition funnel, and a magnetic stir bar. To this solution was added dropwise a portion of (3-chloropropyl)trimethoxysilane (15 g, $0.075 \mathrm{~mol})$ through the addition funnel over a period of $10 \mathrm{~min}$ with vigorous stirring. The stirring was continued for 2 $\mathrm{h}$ until the solution had cooled to room temperature. The reaction mixture was kept at room temperature for another $48 \mathrm{~h}$ without stirring. After 2 days, di- $n$-butyltin dilaurate $(0.15 \mathrm{~g}, 0.24 \mathrm{mmol})$, as a condensation catalyst, was added with stirring. The reaction mixture was maintained at room temperature for 2 days until a white crystalline precipitate appeared. The solution was filtered, and the crystals were collected, washed several times with methanol, and dried under vacuum. Spectra results were in accordance with previously reported data. [16]

${ }^{1} \mathrm{H}$ NMR $\left(\mathrm{CDCl}_{3}, 298 \mathrm{~K}, 300 \mathrm{MHz} ; \mathrm{ppm}\right): 0.78$ (t, $\left.16 \mathrm{H}, \mathrm{SiCH}_{2}\right) ; 1.84$ (q, $\left.16 \mathrm{H}, \mathrm{CH}_{2}\right) ; 3.53$ (t, 16H, $\left.\mathrm{CH}_{2} \mathrm{Cl}\right) .{ }^{13} \mathrm{C} \mathrm{NMR}\left(\mathrm{CDCl}_{3}, 298 \mathrm{~K}, 75.5 \mathrm{MHz}\right.$; ppm): $9.9\left(\mathrm{SiCH}_{2}-\right) ; 26.4\left(-\mathrm{CH}_{2}-\right) ; 47.1\left(-\mathrm{CH}_{2} \mathrm{Cl}\right) .{ }^{29} \mathrm{Si} \mathrm{NMR}\left(\mathrm{CDCl}_{3}, 298\right.$ K, $59.6 \mathrm{MHz} ; \mathrm{ppm}):-67.28$.

Synthesis of octakis (3-azidopropyl)octasilsesquioxane (POSS-N $\mathbf{N}_{3}$ ): [17] POSS-Cl (0.935 mmol, $0.98 \mathrm{~g})$ and $\mathrm{NaN}_{3}(2.13 \mathrm{~g})$ were added to a flask equipped with a magnetic stirrer along with $17 \mathrm{~mL}$ of anhydrous $N$, $\mathrm{N}$-dimethylformamide (DMF). The reaction was carried out at $120^{\circ} \mathrm{C}$ for $48 \mathrm{~h}$. After completion of the reaction, distilled water was added, and the mixture was extracted with $\mathrm{CH}_{2} \mathrm{Cl}_{2}$. Organic layers were dried over anhydrous sodium carbonate, filtered, and concentrated under reduced pressure to obtain the desired product as a yellow viscose liquid. Spectra results were in accordance with previously reported data. [17]

${ }^{1} \mathrm{H}$ NMR $\left(\mathrm{CDCl}_{3}, 500 \mathrm{MHz}\right) \delta(\mathrm{ppm}): 0.71-0.74\left(\mathrm{t}, 16 \mathrm{H}, \mathrm{SiCH}_{2}\right)$, 1.66-1.73 (q, 16H, CH2), 3.25-3.28 (t, $\left.16 \mathrm{H}, \mathrm{CH}_{2} \mathrm{~N}_{3}\right) .{ }^{13} \mathrm{C} \mathrm{NMR}\left(\mathrm{CDCl}_{3}\right.$, $125 \mathrm{MHz}) \delta(\mathrm{ppm}): 8.95\left(\mathrm{SiCH}_{2}-\right), 22.42\left(-\mathrm{CH}_{2}\right), 53.36\left(-\mathrm{CH}_{2} \mathrm{~N}_{3}\right) .{ }^{29} \mathrm{Si}$ NMR $\left(\mathrm{CDCl}_{3}, 99 \mathrm{MHz}\right) \delta(\mathrm{ppm})-67.04$.

Synthesis of octakis (3-dansylpropyl)octasilsesquioxane (POSS-D $\mathbf{8}$ ): Under nitrogen atmosphere, to a $10 \mathrm{~mL} \mathrm{DMF/THF} \mathrm{(1:1)} \mathrm{solution} \mathrm{of}$ POSS-N $\mathrm{N}_{3}(0.1 \mathrm{~g}, 9.2 \times 10-5 \mathrm{~mol})$ was added $N$-dansyl propynyl, D $(0.24$ g, $8.3 \times 10-4) . \mathrm{CuBr}(50 \% \mathrm{~mol}$ equivalent) and PMDETA $(50 \% \mathrm{~mol}$ equivalent) were successively added. The reaction mixture was stirred at RT overnight. 0.02 M EDTA was added and extracted with DCM. Organic phase was further washed with deionized water and $\mathrm{Na}_{2} \mathrm{SO}_{4}$ added. After filtration and concentration in a rotary evaporator, further purification was achieved in a column chromatography (Hexane: Ethyl acetate, $30 \%)$ to afford the desired product as a light yellow solid $(0.078 \mathrm{~g}$, yield $78 \%$ ).

${ }^{1} \mathrm{H}$ NMR (300 MHz, $\left.\mathrm{CDCl}_{3}\right) \delta(\mathrm{ppm}): 0.61\left(\mathrm{~m}, 16 \mathrm{H},-\mathrm{SiCH}_{2}\right.$ ), $1.81(\mathrm{~m}$, $16 \mathrm{H}, \mathrm{Si}-\mathrm{CH}_{2} \mathrm{CH}_{2}$ ), 2.8 (s, $48 \mathrm{H},-\mathrm{N}\left(\mathrm{CH}_{3}\right)_{2}$ ), 4.24 (overlapped $16 \mathrm{H}$, $-\mathrm{CH}_{2} \mathrm{~N}-$ ), 4.25 (overlapped $16 \mathrm{H}$, triazole- $\mathrm{CH}_{2} \mathrm{NH}-$ ), $7.15\left(\mathrm{~s}, 8 \mathrm{H},-\mathrm{CH}_{2} \mathrm{NH}\right.$ ) 7.7 (s, 8H, in 1,2,3-triazole), 7.3-7.5, 8.25-8.3, 8.5 (all m, 6H, CH in dansyl aromatic); ${ }^{13} \mathrm{C} \mathrm{NMR}\left(125 \mathrm{MHz}, \mathrm{CDCl}_{3}\right) \delta$ (ppm): 102.5, 107, 116, $118,123,128,131 .{ }^{29} \mathrm{Si} \mathrm{NMR}\left(59.6 \mathrm{MHz}, \mathrm{CDCl}_{3}\right) \delta(\mathrm{ppm})$ : -67.93 (Si-O$\mathrm{Si})$; FT-IR $\left(\mathrm{cm}^{-1}\right)$ : v (CH) 2932.6; (CN) 1646; (NCO) $1644.7 \mathrm{v}(\mathrm{C}=\mathrm{C}-\mathrm{Ar})$ 1741.9; v (Si-O-Si) 1161-1020; MS (API-ESI) $m / z: 3397.40[\mathrm{M}+\mathrm{H}]+$. Elemental analysis: calculated for $\mathrm{C}_{144} \mathrm{H}_{176} \mathrm{~N}_{40} \mathrm{O}_{28} \mathrm{~S}_{8} \mathrm{Si}_{8}$ (MW 3396.40) C 45.12, H 5.80, N 18.47; found C 45.16, H 5.88, N 18.51\%.

Synthesis of octavinylsilsesquioxane (POSS-vinyl): Formation of POSS-vinyl was realized based on literature data. [18] Thus, acidic amberlite of medium porosity (40 g) was washed with concentrated hydrochloric acid, water and methanol before charging it into a $500 \mathrm{~mL}$ flask, which was equipped with a magnetic stirrer. Methanol $(150 \mathrm{~mL})$ was added and stirred at $30^{\circ} \mathrm{C}$. Vinyltrichlorosilane $(4.0 \mathrm{~mL}, 0.04 \mathrm{~mol})$ was added slowly with stirring to the Amberlite methanolic solution. The stirring continued at room temperature for $10 \mathrm{~h}$ during which white microcrystals were deposited on the wall of the flask. Methanol was decanted into a pre-prepared $500 \mathrm{~mL}$ flask (to be reused in the next experiment). Dichloromethane was added to dissolve the microcrystals and the amberlite was filtered out for reuse in subsequent experiments. The solvent was evaporated and the vinyl-T8 microcrystals washed several times with methanol.

${ }^{1} \mathrm{H} \mathrm{NMR}\left(\mathrm{CDCl}_{3}\right) \delta$ (ppm): 5.69-6.15 (m, $\left.\mathrm{H}_{2} \mathrm{C}=\mathrm{CH}-, 24 \mathrm{H}\right) ;{ }^{13} \mathrm{C}$ NMR $\left(\mathrm{CDCl}_{3}\right) \delta$ (ppm): 128.70 (C1), $136.95(\mathrm{C} 2) ;{ }^{29} \mathrm{Si} \mathrm{NMR}\left(\mathrm{CDCl}_{3}\right) \delta(\mathrm{ppm})$ : $-79.8,-80.6\left(-\mathrm{SiCH}=\mathrm{CH}_{2}\right)$.

Synthesis of POSS-S-Cl: POSS-vinyl (2.0 g, $\left.3.16 \times 10^{-3} \mathrm{~mol}\right)$ was dissolved in anhydrous toluene $(15 \mathrm{~mL})$ under $\mathrm{N}_{2}$ atmosphere. The radical initiator AIBN $\left(0.2 \mathrm{~g}, 1.22 \times 10^{-3} \mathrm{~mol}\right)$ was added to POSS-Vinyl solution and the reaction mixture was heated to $40^{\circ} \mathrm{C}$. Then the linker 3chloropropanethiol $\left(2.64 \mathrm{~mL}, 27 \times 10^{-3} \mathrm{~mol}\right)$ was slowly added to the mixture and the reaction was stirred for $13 \mathrm{~h}$ at $60^{\circ} \mathrm{C}$. After cooling the reaction at room temperature, the supernatant was removed, and the gel was solubilized in dichloromethane $(5.0 \mathrm{~mL})$ and precipitated with hexane $(5 \times 50 \mathrm{~mL})$ at $0{ }^{\circ} \mathrm{C}$. Finally, the gel was dried under reduced pressure to give the desired product as transparent viscous gel $(1.97 \mathrm{~g}$, yield 99\%).

${ }^{1} \mathrm{H} \mathrm{NMR}\left(300 \mathrm{MHz}, \mathrm{CDCl}_{3}\right) \delta(\mathrm{ppm}): 1.08\left(\mathrm{~m}, 16 \mathrm{H},-\mathrm{SiCH}_{2}\right)$ ); $2.1(\mathrm{~m}$, $16 \mathrm{H},-\mathrm{SCH}_{2} \mathrm{CH}_{2}$ ); 2.63 (overlapped, $16 \mathrm{H},-\mathrm{SCH}_{2}$ ); 2.65 (overlapped, $\left.16 \mathrm{H}, \mathrm{SiCH}_{2} \mathrm{CH}_{2}-\mathrm{S}-\right) ; 3.71\left(\mathrm{t}, 16 \mathrm{H}, J=6.3,-\mathrm{CH}_{2} \mathrm{Cl}\right) .{ }^{13} \mathrm{C} \mathrm{NMR}(100 \mathrm{MHz}$, $\left.\mathrm{CDCl}_{3}\right) \delta$ (ppm): 42.5, 32.6, 29.8, 26.3, 14.1. ${ }^{29} \mathrm{Si} \mathrm{NMR} \mathrm{(99} \mathrm{MHz)} \delta(\mathrm{ppm})$ : -68. Elemental analysis (\%) for $\mathrm{C}_{40} \mathrm{H}_{80} \mathrm{Cl}_{8} \mathrm{O}_{12} \mathrm{~S}_{8} \mathrm{Si}_{8}$, calculated: $\mathrm{C}=$ 31.64, $\mathrm{H}=5.30 \mathrm{~S}=16.91$; found: $\mathrm{C}=31.89, \mathrm{H}=5.28, \mathrm{~S}=16.55$.

Synthesis of POSS-S-N 3 . POSS-S-Cl $\left(1.5 \mathrm{~g}, 9.9 \times 10^{-4} \mathrm{~mol}\right)$ and excess of $\mathrm{NaN}_{3}(2.0 \mathrm{~g})$ were added to a flask equipped with a magnetic stirrer along with $15 \mathrm{~mL}$ of anhydrous $\mathrm{N}, \mathrm{N}$-dimethylformamide (DMF). The reaction was carried out at $70^{\circ} \mathrm{C}$ for 2 days. After completion of the reaction, distilled water was added, and the mixture was extracted with $\mathrm{CH}_{2} \mathrm{Cl}_{2}$. Organic layers were dried over anhydrous sodium carbonate, filtered, and concentrated under reduced pressure to obtain the desired product as a yellow viscose liquid (1.23 g, Yield $82 \%)$

${ }^{1} \mathrm{H} \mathrm{NMR}\left(300 \mathrm{MHz}, \mathrm{CDCl}_{3}\right) \delta(\mathrm{ppm}): 1.01\left(\mathrm{~m}, 16 \mathrm{H},-\mathrm{SiCH}_{2^{-}}\right) ; 1.90(\mathrm{~m}$, $16 \mathrm{H},-\mathrm{SCH}_{2} \mathrm{CH}_{2}$ ); 2.58 (overlapped, $16 \mathrm{H},-\mathrm{SCH}_{2}$ ); 2.61 (overlapped, $\left.16 \mathrm{H}, \mathrm{SiCH}_{2} \mathrm{CH}_{2}-\mathrm{S}-\right) ; 3.43\left(\mathrm{t}, 16 \mathrm{H}, J=6.0,-\mathrm{CH}_{2} \mathrm{Cl}\right) .{ }^{13} \mathrm{C} \mathrm{NMR}(100 \mathrm{MHz}$, $\mathrm{CDCl}_{3}$ ) $\delta$ (ppm): 41.9, 32.9, 28.8, 25.7, 13.6. ${ }^{29} \mathrm{Si} \mathrm{NMR} \mathrm{(99} \mathrm{MHz)} \delta(\mathrm{ppm})$ : -68. Elemental analysis (\%) for $\mathrm{C}_{40} \mathrm{H}_{80} \mathrm{~N}_{24} \mathrm{O}_{12} \mathrm{~S}_{8} \mathrm{Si}_{8}$, calculated: $\mathrm{C}=$ 30.59, $\mathrm{H}=5.13, \mathrm{~N}=21.41$; found: $\mathrm{C}=30.41, \mathrm{H}=5.11, \mathrm{~N}=21.44$.

Synthesis of POSS-S-D 8 : Under nitrogen atmosphere, $N$-dansyl propynyl, $\mathbf{D}\left(2.25 \mathrm{~g}, 7.8 \times 10^{-3} \mathrm{~mol}\right)$ was added to $10 \mathrm{~mL}$ THF/DMF $(1: 1)$ solution of POSS-S-N $\mathrm{N}_{3}\left(1.23 \mathrm{~g}, 7.8 \times 10^{-4} \mathrm{~mol}\right)$. CuBr $(50 \% \mathrm{~mol}$ equivalent) and PMDETA (50\% mol equivalent) were successively added. The reaction mixture was stirred at RT overnight. 0.02 M EDTA was added and extracted with DCM. Organic phase was further washed with deionized water and $\mathrm{Na}_{2} \mathrm{SO}_{4}$ added. After filtration and concentration in a rotary evaporator, the solid was recrystallized in chloroform/methanol (1:3) to give the desired product as a light yellow solid (1.12 g, Yield 91\%).

${ }^{1} \mathrm{H}$ NMR (300 MHz, $\mathrm{CDCl}_{3}$ ) $\delta$ (ppm): 1.09 (br s, $16 \mathrm{H},-\mathrm{SiCH}_{2^{-}}$); 2.14 (m, $16 \mathrm{H},-\mathrm{SCH}_{2} \mathrm{CH}_{2}$ ); 2.49 (m, $16 \mathrm{H},-\mathrm{SCH}_{2}$ ); 2.61 (m, $16 \mathrm{H}, \mathrm{SiCH}_{2} \mathrm{CH}_{2}-\mathrm{S}-$ ); 2.85 (s, $\left.48 \mathrm{H}, \mathrm{Ar}-\mathrm{N}\left(\mathrm{CH}_{3}\right)_{2}\right) ; 4.15$ (m, $\left.16 \mathrm{H},-\mathrm{SCH}_{2} \mathrm{CH}_{2} \mathrm{CH}_{2}-\mathrm{N}-\right)$; 4.30 (br s, $16 \mathrm{H},-\mathrm{CH}_{2} \mathrm{NH}$ ); 7.1 (br s, $8 \mathrm{H}$, sulfonamide proton $\mathrm{NH}$ ). ${ }^{13} \mathrm{C}$ NMR (100 $\left.\mathrm{MHz}, \mathrm{CDCl}_{3}\right) \delta$ (ppm): 15.1, 25, 38, 45.1, 52, 53.3, 66.2, 116.0, 118.6, $121,128.4,135.8,151 .{ }^{29} \mathrm{Si} \mathrm{NMR}(99 \mathrm{MHz}) \delta(\mathrm{ppm}): 67$. FT-IR $\left(\mathrm{cm}^{-1}\right): \mathrm{v}$ (CH) 2966.6; (CN) 1678; (NCO) 1644.7 v (C=C-Ar) 1741.9; v (Si-O-Si) 1161-1020; MS (API-ESI) $m / z: 3875.98[\mathrm{M}+\mathrm{H}]+$; Elemental analysis (\%) for $\mathrm{C}_{160} \mathrm{H}_{208} \mathrm{~N}_{40} \mathrm{O}_{28} \mathrm{~S}_{16} \mathrm{Si}_{8}$; calculated: $\mathrm{C}=48.56, \mathrm{H}=5.41 \mathrm{~N}=$ 13.98; found: $\mathrm{C}=48.39, \mathrm{H}=5.52, \mathrm{~N}=13.79$. 


\subsection{Calculation of molecular dimension}

The optimized geometries of POSS-D $\mathbf{D}_{\mathbf{8}}$ and POSS-S-D $\mathbf{8}$ were obtained using the MM2 calculation using the CHEMDRAW 3D software (Job type: Minimize energy to Minimum; RMS Gradient of 0.010 ; iterations $=10,000$ ).

\subsection{Photophysical characterization}

Absorption measurements: Steady state absorption spectra were recorded in a JASCO V-630 spectrophotometer. Quartz cells with $1 \mathrm{~cm}$ optical path length and $3 \mathrm{~mL}$ of capacity were employed. Molar coefficient extinction, $\varepsilon$, was determined according to the Lambert-Beer law:

$\mathrm{Abs}=\mathrm{C} \cdot \varepsilon \cdot \mathrm{L}$

Where, Abs is the absorbance of sample, C concentration, and $\mathrm{L}$ the optical path length of the cuvette.

Fluorescence experiments: Emission spectra were recorded on a JASCO FP-8500 spectrofluorometer system, provided with a monochromator in the wavelength range of $200-850 \mathrm{~nm}$. From the intersection between normalized excitation and emission spectra the singlet energy was determined. Fluorescence quantum yields were determined using 9,10-dimethylantracene as standard (0.95, ETOH). Experiments were performed at $22^{\circ} \mathrm{C}$.

$\Phi_{F}=\frac{A_{i}}{A_{s t d}} \cdot \frac{A b s_{s t d}}{A b s_{i}} \cdot \frac{n}{n_{s t d}} \Phi_{F(s t d)}$

where, $A_{i}$ is the fluorescence area of the sample, $A_{\text {std }}$ is the fluorescence area of standard, $\mathrm{Abs}$ and $\mathrm{Abs}_{\text {std }}$ correspond to the absorbance intensity at excitation wavelength of the sample and standard, respectively, and $n$ is the refraction index of the solvent employed. Fluorescence lifetimes were recorded on a PTI (Photon Technology International) fluorometer which includes a pulsed LED excitation source, a sample holder, and a lifetime detector. For lifetime analysis, EasyLife X software was used. The employed LEDs source was $340 \mathrm{~nm}$. The excitation conditions are expressed in the supplementary information.

\subsection{Photostability studies}

The two FLMs (POSS-D $\mathbf{D}_{\mathbf{8}}$ and POSS-S-D $\mathbf{8}$ ) and alkynyl dansyl precursor in THF, were irradiated with a monochromatic light for $60 \mathrm{~min}$ and photostability was monitored by absorption and emission at interval of time. A conservative monochromatic light irradiation of the samples was equally employed in our laboratory and the absorption profiles were monitored. For this, samples $\left(1.0 \times 10^{-5} \mathrm{M}\right)$ were irradiated with Xenon arc lamp at irradiances of $0.039 \mathrm{~W} / \mathrm{cm}^{2}$ and $0.052 \mathrm{~W} / \mathrm{cm}^{2}$.

\subsection{Fingerprint development and imaging}

As far as this study is concerned, fingermarks were collected from 2 voluntary donors (27 years old and 14 years old) and deposited on phone glassy surface. The donor rubbed his thumb on forehead/nose tip and then it was press-stamped on selected substrate, immersed in FLM solution, and rinsed with water or some organic solvents. The developed

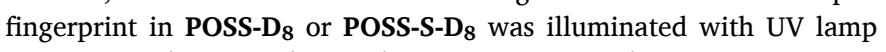
$(365 \mathrm{~nm})$ and image taken with a Samsung smartphone camera.

\section{Results and discussion}

The 3D POSS nanohybrids were synthesized following a three-step procedure (Fig. 1C). In the case of POSS-D8, catalytic treatment of 3chloropropyltrimethoxylsilane by di- $n$-butyltin dilaurate in acidic methanol gave the desired octakis (3-chloropropyl)octasilsesquioxane (POSS-Cl). Then, typical reaction of POSS-Cl with sodium azide in dimethylformamide afforded the corresponding azide-substituted material octakis (3-azidopropyl)octasilsesquioxane (POSS-N $\mathbf{N}_{3}$ ). Last step involved the copper "click" reaction between the resultant POSS- $\mathbf{N}_{\mathbf{3}}$ and 5 -(dimethylamino)- $N$-(2- propynyl)-1-naphthalenesulfonamide ( $N$-dansyl propynyl, D) which had been previously synthesized according to literature. [11] Our desired product, POSS-1 8 , was obtained in high yield $(78 \%)$ as a light yellow solid. Regarding POSS-S-D $\mathbf{D}_{\mathbf{8}}$, the protocol commenced with the octavinylsilsesquioxane (POSS-vinyl) which was fabricated as described in the experimental section. [14] Thus, treatment of POSS-vinyl with a radical initiator (azobisisobutyronitrile, AIBN) in the presence of 3-chloro-1-propanethiol afforded quantitatively the octakis (2-((3-chloropropyl) thio)ethyl)octasilsesquioxane (POSS-S-Cl). Following the same synthetic sequence as abovementioned, POSS-S-Cl was converted into octakis (2-((3-azidopropyl) thio)ethyl)octasilsesquioxane (POSS-S-N $\mathbf{N}_{3}$ ) by azidation in high yield (82\%) and, subsequently formation of the final product, POSS-S-D , was $_{\mathbf{8}}$ obtained in excellent yield (91\%) by the CuBr/PMDETA catalyzed "click" reaction of POSS-S- $\mathrm{N}_{3}$ with $N$-dansyl propynyl $\mathbf{D}$. The chemical

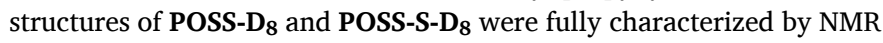
spectroscopy (Figs. S1-S6). For POSS- $\mathbf{D}_{\mathbf{8}}$, characteristic hydrogen resonances of $-\mathrm{SiCH}_{2} \mathrm{CH}_{2} \mathrm{CH}_{2}-\mathrm{N}$, dansyl- $\mathrm{N}\left(\mathrm{CH}_{3}\right)_{2}$, downfield sulfonamide singlet proton $(\delta 7.15)$ and dansyl aromatic protons were clearly identified. Additionally, the presence of the triazole singlet proton $(\delta 7.7)$ evidenced that the "click" reaction was succeeded. Furthermore, ${ }^{29} \mathrm{Si}$ NMR spectrum of POSS-D P $_{\mathbf{8}}$ (Fig. S7) showed a strong single peak, confirming that the $\mathrm{Si}-\mathrm{O}-\mathrm{Si}$ skeleton was not affected during the different synthetic steps. As a matter of fact, FTIR spectra reflected this fact where the structural evolution POSS-Cl $\rightarrow$ POSS- $\mathbf{N}_{\mathbf{3}} \rightarrow$ POSS- $\mathbf{D}_{\mathbf{8}}$ was displayed (Fig. S8). To highlight the disappearance of the azide group after the "click" reaction together with the appearance of carbon-carbon double bond which corresponded to the aromatic dansyl chromophore anchored to the $\mathrm{Si}-\mathrm{O}-\mathrm{Si}$ skeleton. In the case of $\mathbf{P O S S}-\mathbf{S}-\mathbf{D}_{\mathbf{8}}$, protons due to $-\mathrm{SiCH}_{2} \mathrm{CH}_{2}-\mathrm{S}-\left(\mathrm{CH}_{2}\right)_{3}$ - arms of POSS, sulfonamide, triazole, $-\mathrm{N}\left(\mathrm{CH}_{3}\right)_{2}$, $-\mathrm{CH}_{2} \mathrm{NH}-$ and dansyl aromatics were clearly assigned in the ${ }^{1} \mathrm{H}$ NMR spectrum, confirming the chemical structure (Figs. S9-S10). Again, the integrity of the nanocage was confirmed by the presence of one signal in the ${ }^{29} \mathrm{Si} \mathrm{NMR} \mathrm{spectrum} \mathrm{(Fig.} \mathrm{S11),} \mathrm{which} \mathrm{is} \mathrm{typical} \mathrm{of} \mathrm{T8R8} \mathrm{structure}$ corresponding to the T3 silicon units. $[19,20]$ Finally, on the basis of the FTIR spectra (Fig. S12), structural evolution POSS-S-Cl $\rightarrow$ POSS-S-N $\mathbf{N}_{\mathbf{3}} \rightarrow$ POSS-S-D $\mathbf{D}_{8}$ was also observed. Energy-minimized structure of nanohybrids POSS-D $\mathbf{D}_{\mathbf{8}}$ and POSS-S- $\mathbf{D}_{\mathbf{8}}$ showed a molecular dimension of ca. $3.2 \mathrm{~nm}$ and $4 \mathrm{~nm}$, respectively (Fig. S13). Optical properties of POSS-D $\mathbf{8}$ and POSS-S- $\mathbf{D}_{\mathbf{8}}$ were detailed studied in several solvents (Fig. 1D and Table 1).

Similar absorption spectra of both nanohybrids were found in which the absorption band in the UVA region was clearly dominated by the dansyl-type chromophore (Fig.s S14,S15). They presented very high values of Stokes shifts as typically found for dansylated derivatives. [21] The most important difference was attributed to the corresponding molar absorption coefficients $(\varepsilon)$, being remarkably higher in the case of POSS-D $\mathbf{D}_{\mathbf{8}}$ than those for POSS-S-D $\mathbf{D}_{\mathbf{8}}$. On the contrary, fluorescence quantum yields $\left(\Phi_{\mathrm{F}}\right)$ POSS-S-D $\mathbf{D}_{\mathbf{8}}$ were found to be in general 2 times higher than the values observed for nanohybrid POSS-D $\mathbf{D}_{\mathbf{8}}$, with the occurrence that the sulfur bridge may influence in the radiative and non-radiative pathways of the material. As a general trend, higher values of $\Phi_{\mathrm{F}}$ were detected in moderately polar solvents. It was noteworthy that the $\Phi_{\mathrm{F}}$ of POSS-S- $\mathbf{D}_{\mathbf{8}}$ was found to be unity in DCM, indicating no energetic losses. A satisfactory fitting was obtained by considering a biexponential function for the emission decay traces of POSS-D $_{\mathbf{8}}$ and POSS-S-D $\mathbf{D}_{\mathbf{8}}$ (Table 2 and Figs. S16,S17). This was in full agreement with previously reported data [8] for similar POSS nanohybrid containing only one dansyl chromophore. Thus, an intramolecular charge transfer (ICT) state (shorter lifetimes) and possible aggregates (longer lifetimes) could be the responsible of these two emissive lifetimes. However, contribution of the longer lifetime component was actually in the same extend or even higher, especially in moderately polar solvents, indicating unambiguously formation of 
Table 1

Photophysical properties of POSS-D $\mathbf{8}$ and POSS-S-D $\mathbf{8}$.

\begin{tabular}{|c|c|c|c|c|c|c|c|c|c|c|c|c|c|c|}
\hline \multirow[t]{2}{*}{ solvent } & \multicolumn{7}{|l|}{ POSS-D 8} & \multicolumn{7}{|c|}{ POSS-S-D 8} \\
\hline & ${ }^{\mathrm{a}} \lambda_{\mathrm{abs,max}}$ & ${ }^{\mathrm{a}} \lambda_{\mathrm{em}, \max }$ & ${ }^{\mathrm{b}} \varepsilon$ & ${ }^{\mathrm{c}}$ Stokes & ${ }^{\mathrm{d}} \mathrm{E}_{\mathrm{S}}$ & $\Phi_{\mathrm{F}}$ & $\overline{\Phi_{\text {nrad }}}$ & ${ }^{\mathrm{a}} \lambda_{\mathrm{abs}, \max }$ & ${ }^{\mathrm{a}} \lambda_{\mathrm{em}, \max }$ & ${ }^{\mathrm{b}} \varepsilon$ & ${ }^{\mathrm{c}}$ Stokes & ${ }^{\mathrm{d}} \mathrm{E}_{\mathrm{S}}$ & $\Phi_{\mathrm{F}}$ & $\overline{\Phi_{\text {nrad }}}$ \\
\hline DMF & 338 & 519 & 54,510 & 10,328 & 67.4 & 0.33 & 0.67 & 335 & 519 & 2998 & 10,582 & 67.3 & 0.91 & 0.09 \\
\hline ACN & 338 & 522 & 40,350 & 10,429 & 66.5 & 0.31 & 0.69 & 339 & 522 & 2456 & 10,341 & 66.6 & 0.64 & 0.26 \\
\hline THF & 341 & 506 & 62,019 & 9562 & 70.2 & 0.50 & 0.50 & 340 & 509 & 5469 & 9765 & 68.5 & 0.70 & 0.30 \\
\hline DCM & 341 & 512 & 57,848 & 9794 & 67.0 & 0.46 & 0.54 & 340 & 514 & 3675 & 9956 & 66.9 & 1 & 0 \\
\hline
\end{tabular}

${ }^{\text {a }}$ In $\mathrm{nm}$.

b In $\mathrm{M}^{-1} \mathrm{~cm}^{-1}$.

c In $\mathrm{cm}^{-1}$.

d In kcal $\mathrm{mol}^{-1}$.

Table 2

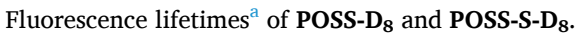

\begin{tabular}{|c|c|c|}
\hline \multirow[t]{2}{*}{ solvent } & POSS-D 8 & POSS-S-D 8 \\
\hline & $\tau_{\mathrm{F}}\left(\tau_{1} ; \tau_{2}\right)$ & $\tau_{\mathrm{F}}\left(\tau_{1} ; \tau_{2}\right)$ \\
\hline DMF & 11.7 (53\%); $25.4(47 \%)$ & $13.1(62 \%) ; 31.1(38 \%)$ \\
\hline ACN & 11.7 (77\%); 27.5 (23\%) & 13.2 (81\%); $36.6(19 \%)$ \\
\hline THF & $10.1(53 \%) ; 23.8(47 \%)$ & $11.1(60 \%) ; 29.4(40 \%)$ \\
\hline DCM & $11.6(40 \%) ; 26.2(60 \%)$ & $12.3(48 \%) ; 29.8(52 \%)$ \\
\hline
\end{tabular}

${ }^{\text {a }}$ In ns; in brackets the contribution of each lifetime.

aggregates. As a premise, it could evidence for enhancing the fluorescence quantum yield and stability of the nanohybrids.

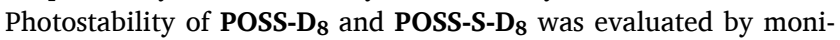
toring their absorption spectra before and after $(60 \mathrm{~min})$ monochromatic light irradiation $\left(\lambda_{\text {irr }}=340 \mathrm{~nm}\right)$ in THF as solvent (Fig. 2). Hence, the absorption spectra of both materials were completely similar even after $60 \mathrm{~min}$ of continuous photolysis, showing excellent photostability. In order to use more sensitive analytical technique, emission spectra were also recorded before and after irradiation (Fig. S18). Here, POSS-D $\mathbf{D}_{\mathbf{8}}$ and POSS-S-D 8 retained the $90 \%$ and $86 \%$, respectively, of the fluorescence intensity.

A judicious balance of hydrophobic and $\pi-\pi$ interactions have been recognized in previous reports for the application of FLMs in LF detection [8-10]. Accordingly, our FLMs were designed based on the combination of a Si-O-Si skeleton and multiple dansyl scaffolds. Fig. 3 shows images corresponding to fresh ( 0 day) and aged fingerprints (i.e. stored at RT for 60 days) (see ESI for details). While undeveloped fingerprint patterns were hardly visible under UV (365 $\mathrm{nm}$ ) or visible light, those developed under diluted solution of POSS-D $\mathbf{8}$ or POSS-S-D P $_{\mathbf{8}}$ apparently exhibited enhanced legibility due to greater contrast between the fluorescent ridge and non-fluorescent furrow. Importantly, the brightness, contrast and general visual legibility remained intact for at least 60 days, indicating a very good photostability of both FLMs. This is ascribed to the structural hydrophobic features of the nanohybrids, which provide an optimal affinity to the amino acid-based oily compounds present in the fingerprints through hydrogen bonding (e.g. $\mathrm{S}=\mathrm{O} \times \times \times \times \mathrm{H}-\mathrm{N}$ (amino acid)). [8,22,23] Moreover, enlarged areas showed whorl, bifurcation, and ridge ending (Fig. 3, right side), which fulfill the requirements for fingerprint identification.

\section{Conclusions}

In summary, two novel octa-dansyl fluorescently labeled POSS (POSS-D8 and POSS-S-D8) have been easily synthesized via "click" chemistry. These nanohybrids were fully characterized and the photophysical study revealed significantly higher molar absorption coefficient for POSS-D8, while the fluorescence quantum yield was 2 times higher in the case of POSS-S-D8. Both FLMs displayed exceptionally distinguished photostability well above that of the $N$-dansyl propynyl precursor. The two photoresponsive octadansyl labeled POSS enabled the detection of latent fingerprints on phone glassy surfaces with very good
A

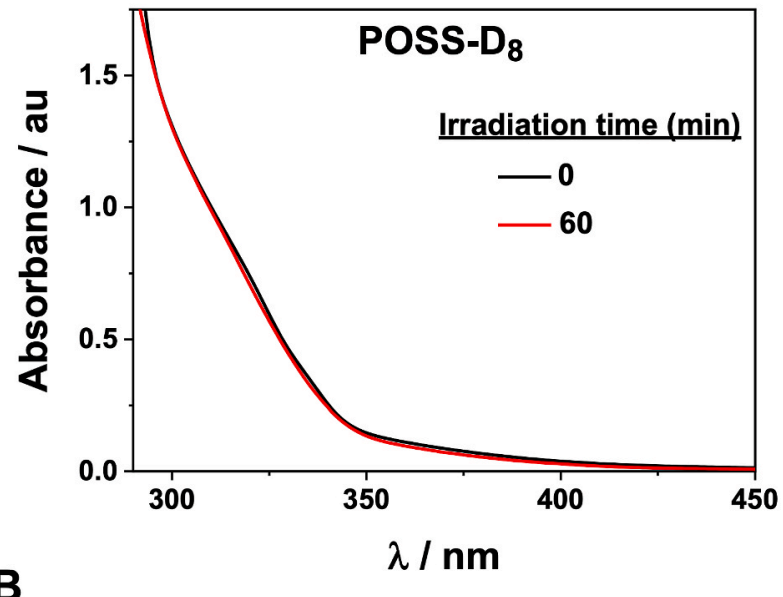

B

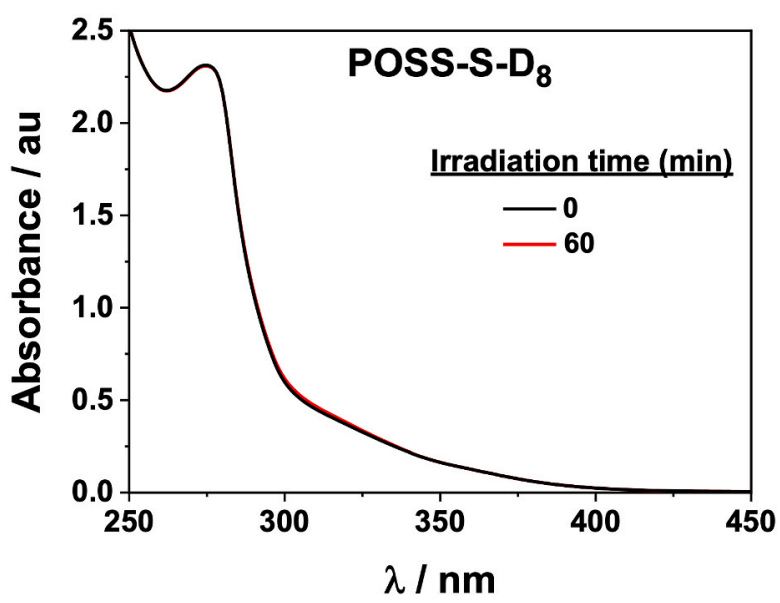

Fig. 2. Absorption spectra of A) POSS-D $\mathbf{8}(0.004 \mathrm{mM})$ and B) POSS-S-D $\mathbf{8}(0.04$ $\mathrm{mM})$ in aerated THF before and after monochromatic light irradiation $\left(\lambda_{\text {irr }}=\right.$ $340 \mathrm{~nm}$ ).

legibility according to the requirements for forensic applications.

\section{Author statement}

Enock O. Dare: Conceptualization, Methodology, preparation of materials and characterization, Writing - original draft. Victoria Vendrell-Criado: Photophysical characterization. M. Consuelo Jiménez: Supervision photophysical characterization, proof-reading manuscript. Raúl Pérez-Ruiz: Supervision, Formal analysis, photophysical characterization, photophysical data analysis, writing manuscript. David Díaz Díaz: Conceptualization, Methodology, Supervision, Writing - original 


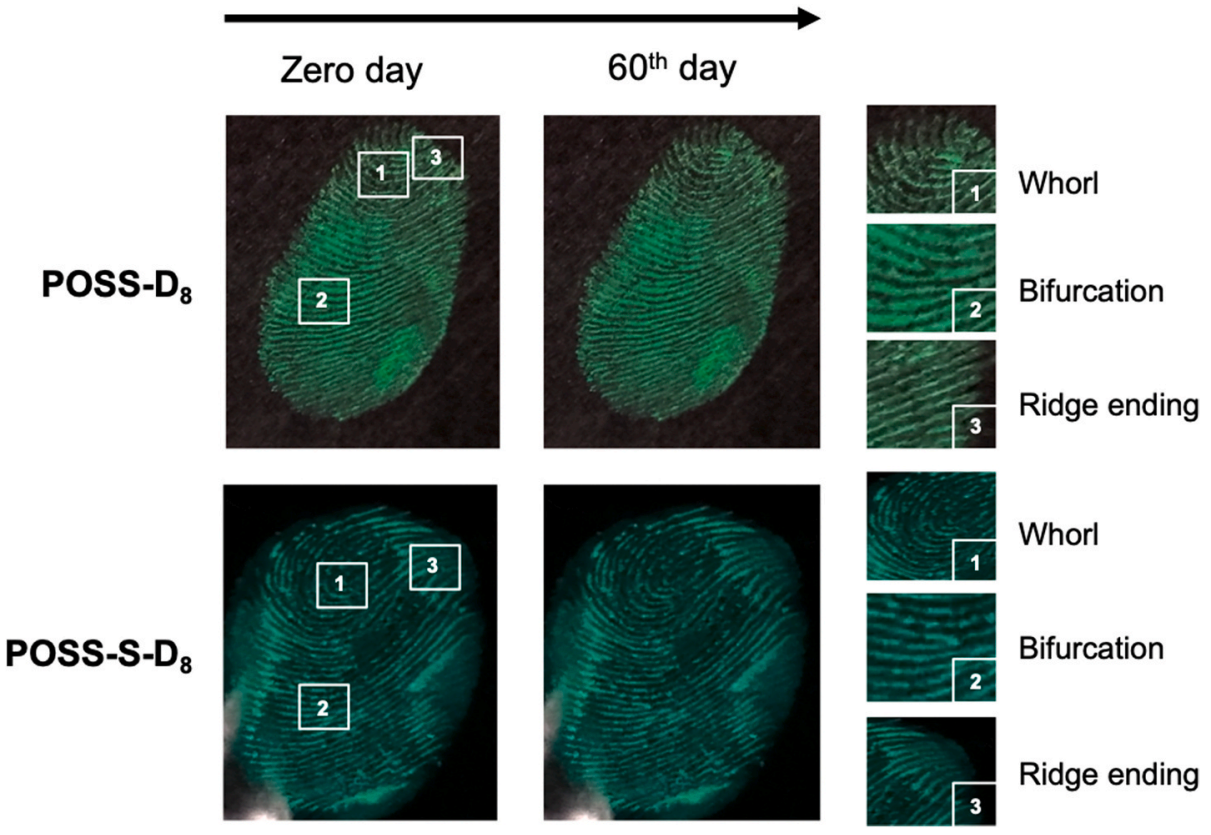

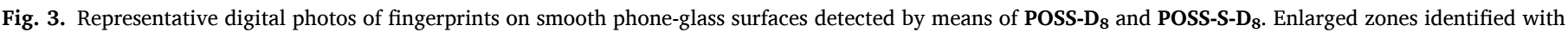
numbers are given on the right.

draft, project supervision, writing and design manuscript.

\section{Declaration of competing interest}

The authors declare that they have no known competing financial interests or personal relationships that could have appeared to influence the work reported in this paper.

\section{Acknowledgment}

Financial support by the Alexander von Humboldt Foundation (Georg Forster Research Fellowship to E.O. Dare), Generalitat Valenciana (CIDEGENT/2018/044) and Universität Regensburg is gratefully acknowledged. Laboratory assistance from MSc A. Abramov and Dr. B. Maiti (Universität Regensburg) is deeply acknowledged. D.D.D. thanks the DFG for the Heisenberg Professorship Award and the Spanish Ministry of Science, Innovation and Universities for the Senior Beatriz Galindo Award (Distinguished Researcher; BEAGAL18/00166). D.D.D. thanks NANOtec, INTech, Cabildo de Tenerife and ULL for laboratory facilities.

\section{Appendix A. Supplementary data}

Supplementary data to this article can be found online at https://doi. org/10.1016/j.dyepig.2020.108841.

\section{References}

[1] Liu Y, Han F, Li F, Zhao Y, Chen M, Xu Z, Zheng X, Hu H, Yao J, Guo T, Lin W, Zheng Y, You B, Liu P, Li Y, Qian L. Inkjet-printed unclonable quantum dot fluorescent anticounterfeiting labels with artificial intelligence authentication. Nat Commun 2019;10:2409.

[2] Liu K-K, Shan C-X, He G-H, Wang R-Q, Sun Z-P, Liu Q, Dong L, Shen D-Z. Advanced encryption based on fluorescence quenching of $\mathrm{ZnO}$ nanoparticles. J Mater Chem C 2017;5:7167.

[3] Partha K, Subrata B, Prafull P, Chandra ST, Pathik K. Tailoring of structural and photoluminescence emissions by $\mathrm{Mn}$ and Cu co-doping in 2D nanostructures of $\mathrm{ZnS}$ for the visualization of latent fingerprints and generation of white light. Nanoscale 2019;11:2017.

[4] Wang M, Li M, Yu A, Zhu Y, Yang M, Mao C. Fluorescent nanomaterials for the development of latent fingerprints in forensic sciences. Adv Funct Mater 2017;27: 1606243. and references therein.
[5] Kanodarwala FK, Moret S, Spindler X, Lennard C, Roux C. Nanoparticles used for fingermark detection - a comprehensive review. WIREs Forensic Sci 2019;1. e1341, and references therein.

[6] Wu P, Xu C, Hou X, Xu J-J, Chen H-Y. Dual-emitting quantum dot nanohybrid for imaging of latent fingerprints: simultaneous identification of individuals and traffic light-type visualization of TNT. Chem Sci 2015;6:4445.

[7] Li F, Li H, Cui T. One-step synthesis of solid state luminescent carbon-based silica nanohybrids for imaging of latent fingerprints. Opt Mater 2017;73:459.

[8] Dare EO, Vendrell-Criado V, Jiménez MC, Pérez-Ruiz R, Díaz Díaz D. Novel fluorescent labeled octasilsesquioxanes nanohybrids as potential materials for latent fingerprinting detection. Chem J Eur 2020. https://doi.org/10.1002/ chem.202001908.

[9] Fatieiev Y, Croissant JG, Alsaiari S, Moosa BA, Angum DH, Khashab NM. Photoresponsive bridged POSS nanoparticles with tunable morphology for lighttriggered plasmid DNA. ACS Appl Mater Interfaces 2015;7:24993.

[10] Loh XJ, Zhang Z-X, Mya KY, Wu Y-L, He CB, Li J. Efficient gene delivery with paclitaxel-loaded DNA-hybrid polyplexes based on cationic polyhedral oligomeric silsesquioxanes. J Mater Chem 2010;20:10634.

[11] Stücker M, Geil M, Kyeck S, Hoffman K, Rochling A, Memmel U, Altmezer P. Interpapillary lines- the variable part of the human fingerprint. J Forensic Sci 2001; 46:857.

[12] Jones BJ, Reynolds AJ, Richardson M, Sears VG. Nano-scale composition of commercial white powders for development of latent fingerprints on adhesives. Sci Justice 2010;50:150.

[13] Ma RL, Zhao Y, Gao F, Han K. Future direction of latent fingerprints development techniques. Chin J Forensic Sci 2016;2:64.

[14] Friesen JB. Forensic Chemistry: the revelation of latent fingerprints. J Chem Educ 2015;92:497.

[15] Fabrizio B, Daniele F, Marco L, Luca P, Nelsi T Claudio Z. Synthesis and photophysical properties of fluorescent derivatives of methylmercury. Organometallics 1996;15:2415.

[16] Bogdan M, Michal D, Hieronim M, Maciej K. New, effective method of synthesis and structural characterization of octakis(3-chloropropyl)octasilsesquioxane. Organometallics 2008;27:793.

[17] Yuan W, Liu X, Zou H, Ren J. Environment-induced nanostructural dynamicalchange based on supramolecular self-assembly of cyclodextrin and star-shaped poly(ethylene oxide) with polyhedral oligomeric silsesquioxane core. Polymer 2013;54:5374.

[18] Dare EO, Li L-K, Peng J. Modified procedure for improved synthesis of some octameric silsesquioxanes via hydrolytic polycondenzation in the presence of Amberlite ion-exchange resins. Dalton Trans 2006:3668.

[19] Pérez-Ojeda ME, Trastoy B, Rol A, Chiara MD, Garcia-Moreno I, Chiara JL. Controlled click-assembly of well-defined hetero-bifunctional cubic silsesquioxanes and their application in targeted bioimaging. Chem Eur J 2013;19:6630.

[20] Hendan BJ, Marsmann HC. Semipräparative rennung gemischt substituierter Octa(organylsilsesquioxane) mittels Normal-Phase-HPLC und ihre ${ }^{29}$ Si-NMRspektroskopische Unters. J Organomet Chem 1994;483:33. 
[21] Montalti M, Prodi L, Zaccheroni N, Battistini G, Marcus S, Mancin F, Rampazzo E, Tonellato V. Size effect on the fluorescence properties of dansyl-doped silica nanoparticles. Langmuir 2006;22:5877.

[22] Hong C, Rong LM, Yun C, Li JF. Fluorescence development of latent fingerprint with conjugated polymer nanoparticles in aqueous colloidal solution. ACS Appl Mater Interfaces 2017;9:4908.
[23] Chen H, Chang K, Men X, Sun K, Fang X, Ma C, Zhao Y, Yin S, Qin W, Wu C. Covalent patterning and rapid visualization of latent fingerprints with photo-crosslinkable semiconductor polymer dots. ACS Appl Mater Interfaces 2015;7:14477. 